\title{
OBTENÇÃO DE MICROPARTÍCULAS A BASE DE SERICINA E ALGINATO PARA INCORPORAÇÃO DE DICLOFENACO DE SÓDIO
}

\author{
T.A. SOARES ${ }^{1}$, J. M. M. VIDART ${ }^{1}$, T. L. DA SILVA ${ }^{1}$, M. L. GIMENES ${ }^{2}$, \\ M. G. C. da SILVA ${ }^{1}$ e M. G. A. VIEIRA ${ }^{1}$ \\ ${ }^{1}$ Universidade Estadual de Campinas, Faculdade de Engenharia Química \\ ${ }^{2}$ Universidade Estadual de Maringá, Departamento de Engenharia Química \\ E-mail para contato: melissagav@feq.unicamp
}

\begin{abstract}
RESUMO - A fim de pesquisar novas formas de incorporação de fármacos, o presente estudo se dedica a desenvolver técnicas de extração da sericina, a formação da blenda entre esta e o alginato e a incorporação de diclofenaco de sódio. Para tal, extraiu-se a sericina por via física, através de autoclave, e utilizouse de gotejamento em solução de $\mathrm{CaCl} 3 \%$ para se obter as partículas. A partir das partículas produzidas realizaram-se ensaios de incorporação, para definir a eficiência de incorporação do diclofenaco de sódio à blenda.
\end{abstract}

\section{INTRODUÇÃO}

A sericina é uma proteína globular e hidrossolúvel encontrada nos casulos do "Bicho da Seda" (Bombyx mori), sendo geralmente descartada nos processos de degomagem e fiação da seda. Esse descarte pode provocar danos ao meio ambiente, que seriam evitados se a proteína fosse reaproveitada, pois esta possui várias propriedades que vêm despertando o interesse da comunidade científica, como aplicação em cosméticos, suportes para enzimas imobilizadas, suplementação alimentar, materiais médicos e farmacêuticos e fibras funcionais, bem como características antioxidantes, antibacterianas e resistência à radiação ultravioleta (ZHANG, 2002; KONGDEE et al., 2004; MONDAL et a., 2007; ARANWIT et al., 2012).

O alginato é muito utilizado em diversos tipos de indústrias, como farmacêutica, alimentícia, têxtil e de papel, em função de determinadas características, como a biocompatibilidade, bioadesividade e sensibilidade ao $\mathrm{pH}$, que o tornam propício para incorporação de drogas. Desse modo, a blenda entre sericina e alginato é muito favorável para incorporação de fármacos (HWANG et al., 1995; ZHANG et al., 2002; KHANDAI et al., 2010).

O desenvolvimento de novas formas farmacêuticas de liberação modificada, a partir dos princípios ativos já existentes, é uma alternativa que vem sendo adotada para que os medicamentos apresentem maior absorção do ativo e redução dos efeitos colaterais, visto que o desenvolvimento de novos princípios ativos apresenta um elevado custo, sendo, portanto, 
inviável economicamente (ALLEN et al., 2007). O diclofenaco de sódio é uma substância anti-inflamatória não esteroidal, utilizado para reduzir a inflamação e aliviar a dor, funcionando como analgésico em situações de artrites e lesões agudas. O desenvolvimento de novas formas farmacêuticas de liberação modificada pode melhorar o efeito terapêutico deste fármaco, além de reduzir os efeitos colaterais indesejados (SANTOS et al., 2007; KAITH et al., 2011; ALBANEZ, 2012).

Sendo assim, o presente estudo tem como objetivo o desenvolvimento de micropartículas de sericina e alginato, visando avaliar a aplicação do material produzido na incorporação de diclofenaco de sódio em sua estrutura. A sericina foi extraída dos casulos do Bombyx mori e o alginato foi obtido comercialmente. A morfologia do material produzido e sua estrutura química foram avaliadas por microscopia eletrônica de varredura e espectroscopia na região do infravermelho com transformada de Fourier, respectivamente. Para determinar a eficiência de incorporação, ensaios de incorporação foram realizados.

\section{METODOLOGIA}

\subsection{Processo de extração da sericina}

Através da empresa BRATAC, com sede na cidade de Londrina, foram obtidos os casulos do Bombyx mori, que com tesoura e pinça, foram limpos e cortados em pedaços de aproximadamente $1 \mathrm{~cm}^{2}$ de área. Logo depois, foram lavados com água corrente e enxaguados por três vezes com água deionizada. A seguir, os casulos foram colocados em estufa a $50{ }^{\circ} \mathrm{C}$ para a secagem por 12 horas, ou até que atingissem massa constante. Ao serem retirados da estufa, os casulos foram resfriados à temperatura ambiente, sendo colocados em dessecadores com sílica gel, e posteriormente pesados em balança analítica, para serem utilizados nos experimentos de extração. Nesta etapa, os casulos foram colocados em erlenmeyer com água deionizada na razão de $40 \mathrm{~g}$ de casulo para $1 \mathrm{~L}$ de água, e em seguida, conduzidos à autoclave $\mathrm{O}$ processo dura 40 minutos e o ambiente da autoclave deve ser mantido em $1 \mathrm{kgf.cm}{ }^{-2}$ de pressão manométrica e $120^{\circ} \mathrm{C}$ de temperatura, conforme metodologia descrita por Tomadon JR (2011).

Foi utilizado o método de precipitação por congelamento, a fím de realizar o fracionamento da sericina. Sendo assim, a solução de sericina extraída foi acondicionada em ambiente fechado e mantida em temperatura ambiente por aproximadamente 12 horas e, logo em seguida, em congelador comum por um período de 24 horas. Após esse período, a solução foi descongelada e esta passou por uma separação de fases com o sobrenadante contendo proteínas insolubilizadas, sendo que estas foram separadas através de filtração com papel filtro de porosidade $14 \mu \mathrm{m}$. Após a filtração, é possível ajustar a concentração da solução de sericina para $2,5 \%(\mathrm{~m} / \mathrm{v})$, a qual foi utilizada para a formação da blenda e posterior incorporação do fármaco.

\subsection{Incorporação do fármaco}

Como proposto por Silva et al. (2013) para produção da blenda de sericina e alginato, a solução de sericina $2,5 \%(\mathrm{~m} / \mathrm{v})$ foi aquecida em autoclave a $70{ }^{\circ} \mathrm{C}$ por 10 minutos e, então, foi agitada mecanicamente a $4000 \mathrm{rpm}$ em Ultraturrax ${ }^{\circledR}$. A solução esfriou até $55^{\circ} \mathrm{C}$ e adicionou-se alginato a $2 \%(\mathrm{~m} / \mathrm{v})$, mantendo-se a agitação. Após a solubilização do alginato, 
diversas quantidades de diclofenaco de sódio foram adicionadas à blenda $(0,5 \%, 1 \%, 1,5 \%$, $2 \%$ e $3 \%(\mathrm{~m} / \mathrm{v})$ ), originando diferentes formulações (F1, F2, F3, F4 e F5). Por fim, essa solução foi agitada a $8000 \mathrm{rpm}$, até que todo o fármaco fosse dissolvido.

\subsection{Preparação das micropartículas}

Para preparar as micropartículas utilizou-se uma adaptação da metodologia de Khandai et al. (2010) e Silva et al. (2013), sendo esta realizada por gotejamento seguido de reticulação. Através de um sistema de bombas, a blenda entre a sericina e o alginato contendo diclofenaco de sódio foi gotejada, sob agitação magnética, em uma solução de cloreto de cálcio $3 \%(\mathrm{~m} / \mathrm{v})$, ocorrendo rápida gelificação da solução. Depois desse processo, as partículas foram mantidas sob agitação em Jar Test a $80 \mathrm{rpm}$, durante 30 minutos. Por fim, as micropartículas foram lavadas com água deionizada e secas à temperatura ambiente.

\subsection{Ensaios de incorporação}

Para realizar os ensaios de incorporação, uma pequena quantidade de micropartículas secas foi moída em almofariz de porcelana, transferindo-se, em seguida, 0,01 g de micropartículas moídas para um balão volumétrico de $25 \mathrm{~mL}$, onde adicionou-se $15 \mathrm{~mL}$ de metanol. Este balão volumétrico foi conduzido ao ultrassom modelo Brason 1510-USA, onde permaneceu por 30 minutos. Após este período, completou-se o volume do balão com metanol, deixando-o em repouso por 1 hora, para a total sedimentação de toda a suspensão. Decorrido este tempo, uma alíquota de $400 \mu \mathrm{L}$ foi coletada e diluída em um balão volumétrico de $10 \mathrm{~mL}$ com metanol.

A concentração de diclofenaco de sódio presente na solução foi determinada por espectrofotômetro modelo UV mini 1240 Shimadzu - Japão, no comprimento de onda de máxima absorção do diclofenaco de sódio, determinado previamente, equivalente a $282 \mathrm{~nm}$. A eficiência de incorporação foi calculada a partir da Equação 1.

$$
\text { Eficiência de incorporação }=\frac{\text { Concentração de fármaco obtido }}{\text { Concentração de fármaco teórico }} \times 100
$$

\section{RESULTADOS E DISCUSSÕES}

A morfologia das micropartículas de sericina e alginato contendo diclofenaco de sódio foi analisada pela microscopia eletrônica de varredura (MEV), sendo possível verificar a eficiência na formação de partículas, porém constatou-se a presença de bolhas de ar, e acredita-se que essas bolhas sejam em decorrência da agitação a $8000 \mathrm{rpm}$. A Figura 1 apresenta as imagens obtidas por MEV das formulações produzidas. Na Figura 1a é possível verificar a forma da partícula de diclofenaco de sódio, a qual se repete na superfície da micropartícula em (1c) e no corte da mesma em (1d), sendo possível perceber a presença de diclofenaco de sódio na micropartícula. Na Figura 1 b verifica-se a formação esférica das micropartículas. 
Figura 1 - Imagens obtidas por MEV. (a) Diclofenaco de sódio puro. (b) Micropartículas de sericina, alginato e diclofenaco de sódio. (c) Superfície da micropartícula. (d) Corte da micropartícula.

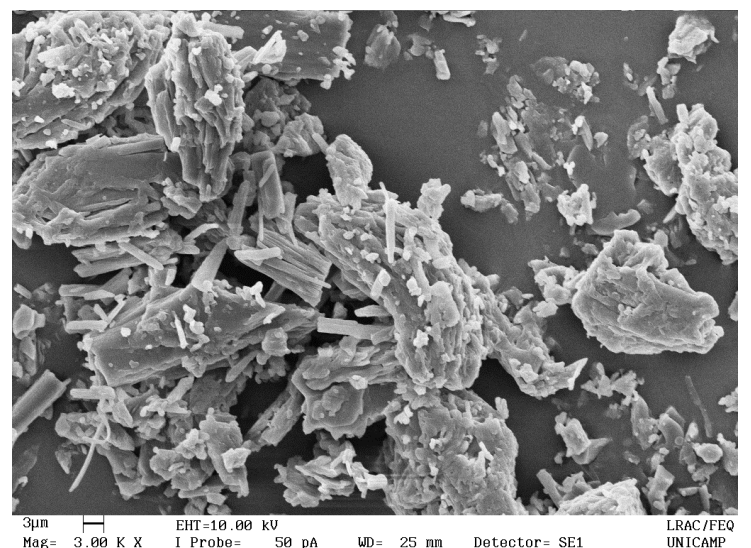

(a)

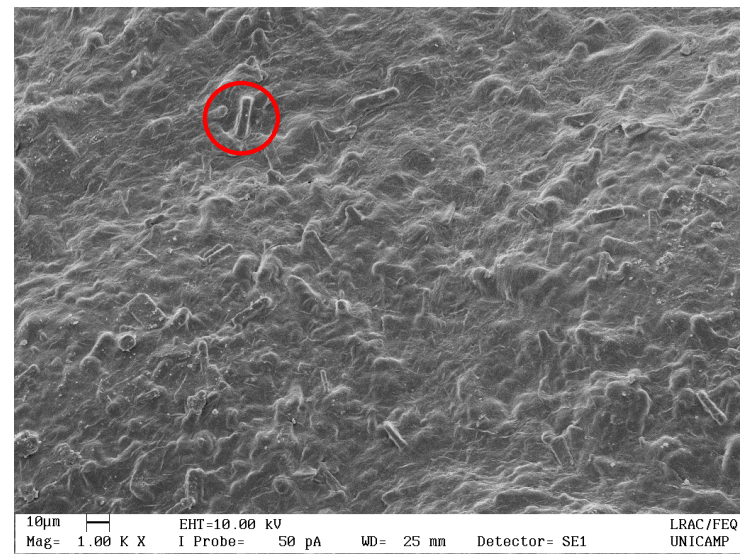

(c)

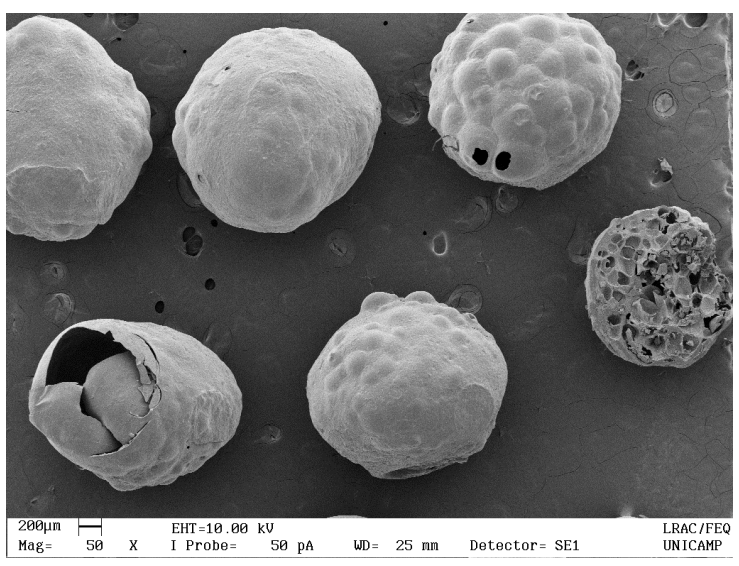

(b)

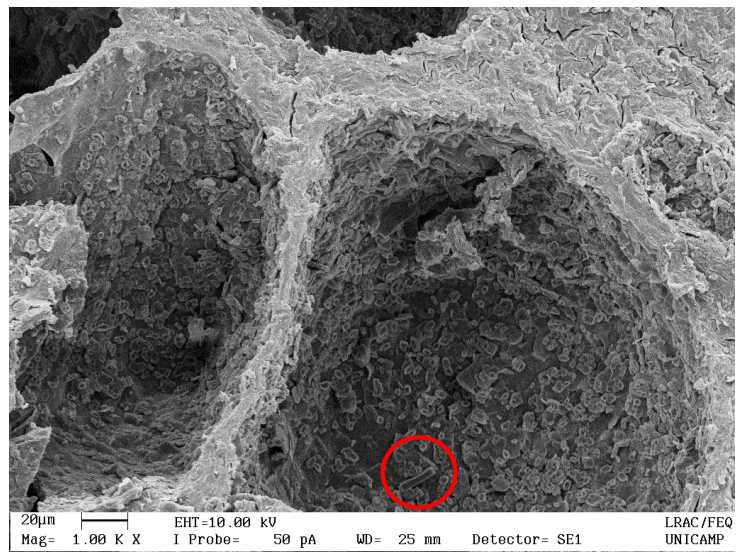

(d)

A partir dos ensaios de incorporação e pela utilização da Equação 1, foi possível verificar a eficiência de incorporação do diclofenaco de sódio à blenda, para as diferentes formulações, sendo os resultados apresentados na Tabela 1.

Tabela 1 - Eficiências dos ensaios de incorporação do fármaco.

\begin{tabular}{c|c|c|c|c}
\hline Formulação & $\begin{array}{c}\text { Sericina } \\
(\mathbf{g})\end{array}$ & $\begin{array}{c}\text { Alginato } \\
(\mathbf{g})\end{array}$ & $\begin{array}{c}\text { Diclofenaco } \\
\mathbf{( g )}\end{array}$ & $\begin{array}{c}\text { Eficiência/rendimento } \\
\mathbf{( \% )}\end{array}$ \\
\hline 1 & 2,5 & 2,0 & 0,5 & 15,58 \\
\hline 2 & 2,5 & 2,0 & 1,0 & 34,95 \\
\hline 3 & 2,5 & 2,0 & 1,5 & 35,72 \\
\hline 4 & 2,5 & 2,0 & 2,0 & 33,95 \\
\hline 5 & 2,5 & 2,0 & 3,0 & 53,80 \\
\hline
\end{tabular}

A análise de FTIR foi realizada com todas as formulações farmacêuticas (F1, F2, F3, F4 e F5), com a blenda entre sericina e alginato sem presença de fármaco (Ser/Alg) e com o 
diclofenaco de sódio puro (DS), e seus espectros estão apresentados na Figura 2. Pode-se perceber que há uma banda mais evidente, conforme destacado na Figura 2, localizada entre $700 \mathrm{~cm}^{-1}$ e $800 \mathrm{~cm}^{-1}$, presente no diclofenaco de sódio, e que se repete nas formulações farmacêuticas. Esta banda de absorção não está presente na blenda de sericina e alginato, assim sendo, pode-se inferir que a incorporação do fármaco foi bem sucedida.

Figura 2 - Bandas de absorção das diferentes formulações, da sericina e alginato e do diclofenaco.

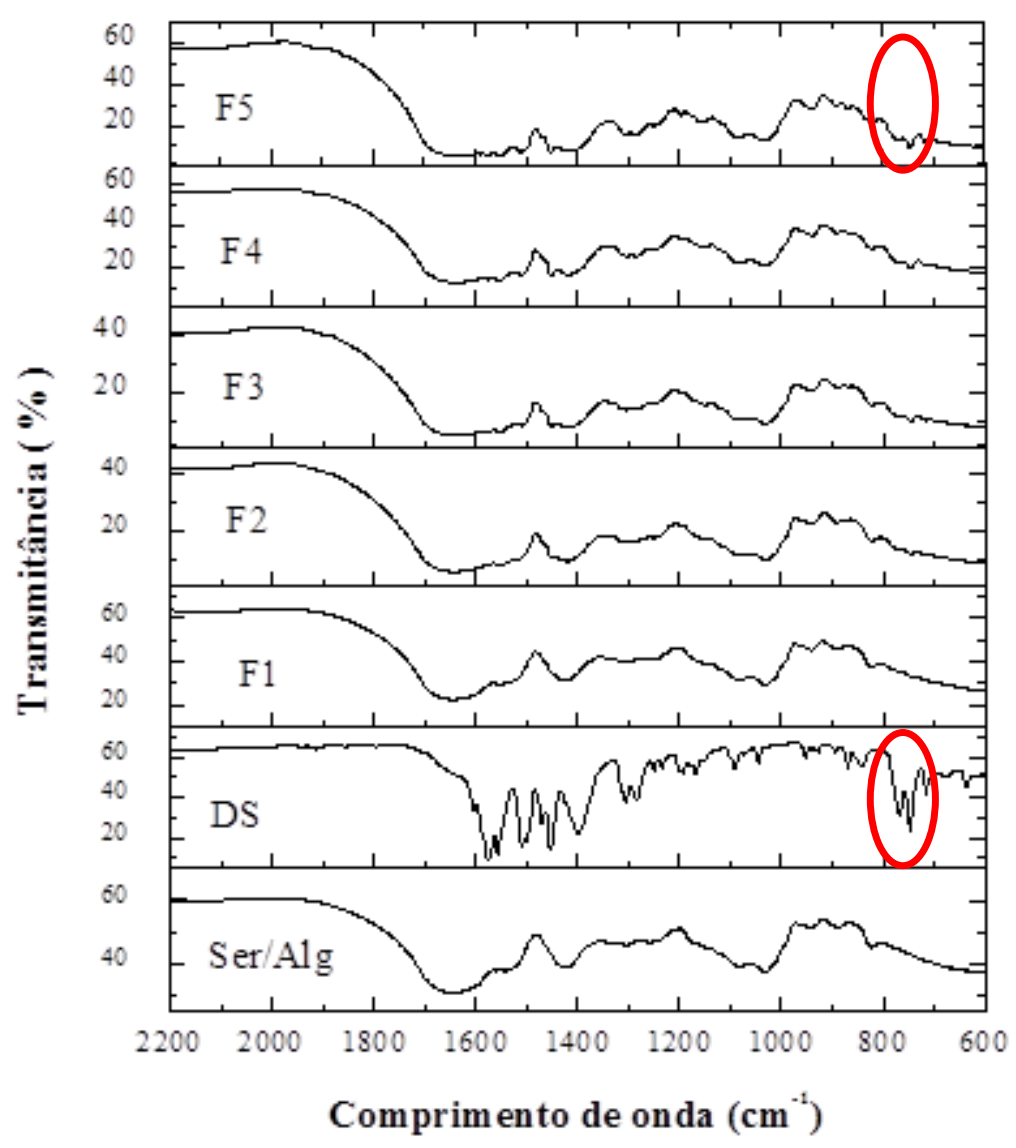

\section{CONCLUSÕES}

Pode-se concluir que o método escolhido para extração da sericina, por via física e autoclave, foi apropriado, pois extraiu a sericina dos casulos de modo eficiente e barato, além de não demandar muito tempo, mesmo que a quantidade de material bruto tenha sido muito maior que o produto final obtido. Em relação à formação das partículas, pode-se dizer, por meio das análises de $\mathrm{MEV}$, que estas foram bem formadas, com exceção a algumas fissuras e bolhas de ar presentes.

Quanto à incorporação de diclofenaco de sódio à blenda de sericina e alginato, pode-se dizer que foi efetiva, mesmo não apresentando uma eficiência muito elevada, principalmente para as partículas com menor quantidade de fármaco adicionada. A efetividade desta 
incorporação pode ser confirmada, além dos ensaios de incorporação, através das análises de MEV e FTIR. Por fim, conclui-se que os métodos até então empregados obtiveram sucesso.

\section{REFERÊNCIAS}

ALBANEZ, R. Recobrimento gastrorresistente de pellets de diclofenaco de sódio em leito fluidizado tipo Wurster. São Paulo: Universidade Estadual de Campinas, Faculdade de Engenharia Química, 2012. 159p. Dissertação (Mestrado).

ALLEN Jr, L. V.; POPOVICH, N. C.; ANSEL, H. C. Formas farmacêuticas e sistemas de liberação de fármacos. $8^{\mathrm{a}}$ ed, Porto Alegre: Ed. Artmed, 2007, 776p.

ARAMWIT, P.; SIRTIENTONG, T.; SRICHNA, T. Potencial applications of silk sericin a natural protein from textile industry by-products. Waste management and Research. v.30, n.3, p.217-224, 2012.

HWANG, S., RHEE, G. J, LEE, K. M., OH, K., KIM, C., Release characteristics of ibuprofen from excipient-loaded alginate gel beads. International Journal of Pharmaceutics. n.116, p. 125-128, 1995.

KHANDAI, M.; CHAKRABORTY, S.; SHARMA, A.; PATTNAIK, S.; PATRA, C. N.; DINDA, S. C.; SEM, K. K. Preparation and evaluation of algino-sericin mucoadhesive microspheres: An approach for sustained drug delivery. Journal of Advanced Pharmaceutical Research, v.1, p.48-60, 2010.

KONGDEE, A., BECHTOLD, T., TEUFEL, L. Modification of Cellulose Fiber with Silk Sericin. Journal of Applied Polymer Science, v. 96, p.1421-1428, 2004.

MONDAL, M.; TRIVEDY, K.; KUMAR, N. The silk proteins, sericin and fibroin in silkworm, Bombyx mori Linn. - A review. Caspian Journal of Environmental Sciences, v.5, n.2, p.63-76, 2007.

SILVA, T. L.; GIMENES, M. L.; VIEIRA, M. G. A.; SILVA, M. G. C. Extração de sericina de casulos do bicho da seda (bombyx mori) e formação de partículas a base de sericina e alginato. XXXVI Congresso Brasileiro de Sistemas Particulados. Maceió, 2013.

TOMADON JR, J. Obtenção da proteína sericina, com alta massa molecular, a partir de casulos Bombyx mori. Paraná: Universidade Estadual de Maringá, 2011. 172 p. Dissertação (Mestrado).

ZHANG, Y. Q. Applications of natural silk protein sericin in biomaterials. Biotechnology Advances. v.20, p.91-100, 2002.

\section{AGRADECIMENTOS}

Os autores agradecem ao CNPq e FAPESP pelo apoio financeiro, e à empresa BRATAC pelo fornecimento dos casulos. 